\title{
Perbedaan Hasil Belajar Antara Siswa yang Menggunakan Simulasi komputer dengan Hands On Activity Pada Materi Momentum Impuls dan Tumbukan Kelas XI SMA Negeri 3 Palu
}

\author{
Wayan Jefry Triana, Muslimin, dan Yusuf Kendek \\ Yhan.jefryan@gmail.com \\ Program Studi Pendidikan Fisika FKIP Universitas Tadulako \\ Jl. Soekarno Hatta Km. 9 Kampus Bumi Tadulako Tondo Palu - Sulawesi Tengah
}

\begin{abstract}
Abstrak - Penelitian ini bertujuan untuk mengetahui ada tidaknya perbedaan hasil belajar siswa dalam belajar konsep fisika mengunakan simulasi komputer dengan hans on activity Pada Materi Momentum Impuls dan Tumbukan Kelas XI SMA Negeri 3 Palu. Jenis penelitian ini merupakan kuasi eksperimen dengan desain quasi experimental designs. Populasi penelitian adalah siswa kelas XI SMA Negeri 3 Palu. Pengambilan sampel dilakukan secara Cluster Random Sampling dengan sampel penelitian adalah kelas XI IPA 1 sebagai kelas eksperimen (HOA) dan kelas XI IPA 2 sebagai kelas eksperimen (CS). Instrumen penelitian berupa tes konsep dasar siswa pada salah satu meteri momentum, impuls dan tumbukan Tes berbentuk pilihan ganda yang dilaksanakan di akhir (posttest) perlakuan telah divalidasi oleh validator. Skor rata-rata yang di peroleh pada kelas eksperimen (CS) adalah 14,41 sedangkan pada kelas eksperimen (HOA) adalah 12,25. Nilai signifikansi hasil uji hipotesis diperoleh lebih besar dibandingkan dengan nilai t tabel atau $3,60>1,67$, sehingga $\mathrm{H}_{1}$ diterima dan $\mathrm{H}_{0}$ ditolak. Hasil ini menunjukkan bahwa terdapat perbedaan hasil belajar siswa dalam belajar konsep fisika mengunakan simulasi komputer dengan hans on activity Pada Materi Momentum Impuls dan Tumbukan Kelas XI SMA Negeri 3 Palu.
\end{abstract}

Kata Kunci: Hasil Belajar, Simulasi Komputer, Hands On Activity

\section{PENDAHULUAN}

Pendidikan memegang peranan penting dalam suatu Negara untuk menjamin kelangsungan hidup negara dan bangsa, karena pendidikan merupakan wahana untuk mengembangkan kualitas sumber daya manusia. Upaya agar manusia dapat mengembangkan potensi yang ada pada dirinya melalui proses pembelajaran. Dan dalam rangka meningkatkan mutu pendidikan diperlukan adanya proses belajar mengajar yang optimal sehingga diperoleh hasil belajar yang optimal pula. Untuk mencapai tujuan tersebut dibutuhkan kesadaran baik peserta didik sebagai subyek yang harus terlibat secara aktif dalam proses belajar maupun guru sebagai pendidik, karena belajar pada hakikatnya merupakan usaha yang dilakukan secara sadar oleh seseorang untuk menghasilkan perubahan tingkah laku dalam dirinya sendiri baik dalam bentuk pengetahuan dan keterampilan baru maupun dalam bentuk sikap dan nilai yang positif.[1]

Perkembangan teknologi adalah sesuatu yang tidak bisa dihindari dalam kehidupan ini. Fisika berperan penting dalam perkembangan teknologi, karena perkembangan atau kemajuan teknologi akan berjalan sesuai dengan perkembangan Fisika. Manusia dapat menciptakan inovasi-inovasi terbaru yang berupa produk teknologi yang digunakanuntuk memudahkan dalam memecahkan berbagai masalah dalam kehidupan.

Seiring berkembangnya teknologi yang ada sekarang ini, berimbas juga pada perkembangan ilmu pengetahuan.[2] Pelaksanaan Kurikulum pembelajaran menuntut guru untuk aktif, kreatif dan inovatif dalam melaksanakan tugas pembelajaran sehingga para siswa tidak merasa bosan dan diharapkan lebih memahami materi yang disampaikan. Berbagai fasilitas saat ini telah tersedia untuk menunjang proses pembelajaran. Salah satu aplikasi teknologi pembelajaran yang saat ini mulai populer adalah simulasi komputer yang menyediakan simulasi fenomena fisik berbasis penelitian secara gratis, menyenangkan, interaktif dan bisa mengajak siswa untuk belajar dengan cara-cara mengeksplorasi secara langsung. Dengan program ini, siswa bisa lebih real mengamati fenomena yang ada.

Penggunaan model pembelajaran Hans on activity merupakan sebagai strategi untuk membantu membimbing siswa mencapai kompetensi yang diharapkan dan mampu meningkatkan motivasi dan mencapai hasil belajar yang maksimal. yang menuntut peserta didik untuk aktif dalam pembelajaran dan mempersyaratkan kompetensi sebagai hasil belajar yang meliputi tiga ranah yaitu pengetahuan, ketrampilan dan sikap. Dan salah satu Indikator bahwa mutu pendidikan baik 
ketika peserta didik telah mampu untuk memecahkan masalah yang dihadapi dalam kehidupan sehari-hari. Kemampuan itu dikembangkan melalui pengalaman langsung dengan melakukan penyelidikan atau percobaan di laboratorium atau di kelas. Penyelidikan atau percobaan yang dilaksanakan di laboratorium maupun di kelas dapat meningkatkan keterampilan proses peserta didik.[3]

Berdasarkan hasil observasi awal di Kelas $X$ SMAN 3 Palu diperoleh. bahwa pembelajaran secara umum yang berlangsung masih menggunakan pembelajaran konvensional. Dalam pembelajaran konvensional, peserta didik menerima pelajaran hanya dengan mendengarkan ceramah dari guru, mencatat dan mengerjakan tugas sehingga peserta didik tidak memiliki kesempatan untuk menggembangkan pengetahuan dan kemampuan berfikir kritis. Berdasarkan informasi dari guru mata pelajaran fisika sebagian besar peserta didik untuk kelas $X$ mempunyai minat dan tingkat perhatian yang kurang terhadap pelajaran fisika. Mereka merasa pelajaran fisika adalah pelajaran yang sukar pemahamannya, Selain itu guru jarang melaksanakan kegiatan praktikum karena masih berorientasi terselesaikannya materi. Hal ini menyebabkan peserta didik tidak terlibat dalam aktivitas kerja ilmiah yang berarti keterampilan proses peserta didik belum dikembangkan. Permasalahan tersebut berakibat peserta didik kurang dapat memahami konsep materi tersebut. peserta didik masih mengalami kesulitan untuk berfikir aktif, kreatif, kritis dan terlebih secara teliti.

Penggunaan Simulasi komputer terhadap siswa diharapkan akan lebih bisa memahami pokok bahasan yang di ajarkan dan hal-hal yang terkait di dalamnya karena simulasi komputer memiliki fasilitas yang interaktif dan eksploratif. Dan Pembelajaran hands on activity menekankan agar peserta didik aktif dan memberikan kebebasan kepada siswa dalam mengkonstruk pemikiran dan temuan selama melakukan aktivitas sehingga siswa melakukan sendiri dengan tanpa beban, menyenangkan dan motivasi yang tinggi.

Simuasi komputer dan hands on activity sangat baik digunakan untuk meningkatkan hasil belajar yang dimiliki siswa, dari uraian di atas peneliti ingin menerapkan penggunaan simulasi komputer dan hands on activity, untuk mengetahui bagaimana perbadingan hasil belajar antara siswa yang menggunakan simulasi komputer dengan hands on activity pada pembelajaran konsep fisika.

\section{METODE PENELITIAN}

Jenis penelitian ini adalah kuasi eksperimen. Pada penelitian ini di gunakan 2 kelas sebagai sampel. Adapun desain penelitian yang digunakan adalah sebagai berikut

Desain penelitian ini digambarkan pada Tabel 1. [5]

TABEL 1 DESAIN PENELITIAN

\begin{tabular}{lcc}
\hline \multicolumn{1}{c}{ Kelas } & Perlakuan & $\begin{array}{c}\text { Tes } \\
\text { akhir }\end{array}$ \\
\hline Eksperimen & $\mathrm{X}_{1}$ & $\mathrm{X}_{1: \mathrm{X}_{2}}$ \\
Kontrol & $\mathrm{X}_{2}$ & \\
\hline
\end{tabular}

Keterangan :

$\mathrm{X}_{1}$ : Model pembelajaran Simulasi Komputer

$X_{2} \quad$ : Pembelajaran Hands On Activity

$\mathrm{X}_{1:} \mathrm{X}_{2} \quad$ : Tes statistik uji hipotesis

Penelitian dilakukan di SMA Negeri 3 Palu. Populasi dalam penelitian ini adalah siswa kelas XI IPA SMA Negeri 3 Palu tahun pelajaran 2015/2016 yang terdiri dari 6 kelas. Sampel dalam penelitian ini adalah kelas XI IPA 1 yang berjumlah 38 siswa dan XI IPA 2 yang berjumlah 40 siswa. Teknik pengambilan sampel yang digunakan adalah purposive sampling, yaitu teknik penentuan sampel dengan pertimbangan tertentu.

Instrumen yang digunakan dalam penelitian ini adalah tes hasil belajar yang telah divalidasi oleh validator ahli. Analisis data hasil penelitian menggunakan uji normalitas, uji homogenitas, $u j i$ hipotesis $(u j i-t)$.

\section{HASIL DAN PEMBAHASAN}

\section{A. Hasil Penelitian}

Pada penelitian ini proses validasi dilakukan oleh validator ahli. Dimana soal yang telah dibuat dikonsultasikan kepada validator ahli. Instrumen soal yang dibuat berjumlah 8 soal, kemudian berdasarkan hasil validitas ahli disetujui 7 soal yang selanjutnya 7 soal tersebut digunakan sebagai soal pretest dan postest pada siswa kelas VIII SMP Negeri 16 Palu.

TABEL 2 DESKRIPSI SKOR TES HASIL BELAJAR SISWA UNTUK KELAS EKSPERIMEN CS DAN KELAS EKSPERIMEN HOA

\begin{tabular}{ccc}
\multicolumn{2}{c}{ EKSPERIMEN CS DAN KELAS EKSPERIMEN HOA } \\
\cline { 2 - 3 } Uraian & \multicolumn{2}{c}{ Posttest } \\
\cline { 2 - 3 } & $\mathrm{CS}$ & HOA \\
\hline Sampel $(\mathrm{n})$ & 38 & 40 \\
Nilai maksimum & 18 & 18 \\
Nilai minimum & 8 & 7 \\
Skor rata-rata & 14,41 & 12,25 \\
Standar deviasi & 2,77 & 2,87 \\
\hline
\end{tabular}

Berdasarkan hasil pemberian pretest dan posttest pada kelas eksperimen yang berjumlah 30 siswa dan kelas kontrol yang berjumlah 30 
siswa diperoleh nilai maksimum, nilai minimum, nilai rata-rata dan simpangan baku seperti terlihat pada Tabel 2 .

Hasil perhitungan analisis uji normalitas Posttest dapat dilihat pada Tabel 3.

TABEL 3 HASIL UJI NORMALITAS POSTTEST KELAS EKSPERIMEN CS DAN

\begin{tabular}{ccc} 
& \multicolumn{2}{c}{ KELAS EKSPERIMEN HOA } \\
\hline \multirow{2}{*}{ Uraian } & Posttest & \\
\cline { 2 - 3 } & CS & HOA \\
\hline Nilai $\chi^{2}$ hitung & 6,76 & 2,71 \\
Nilai $\chi^{2}$ tabel & 7,81 & 7,81 \\
Keputusan & distribusi normal & distribusi \\
& & normal
\end{tabular}

Berdasarkan hasil uji normalitas pada tabel 3 dengan derajat kebebasan $\mathrm{dk}=\mathrm{k}-3=6-3=$ 3 dengan peluang $(1-\alpha)=1-0,05=0,95$ pada taraf signifikansi $\alpha=0,05$, diperoleh nilai $X^{2}$ Hitung postest kelas eksperimen Simulasi Komputer dan Eksperimen Hands On Activity masing-masing 6,76 dan 2,71 dengan $X^{2}$ tabel 7,81 sehingga $X^{2}$ Hitung $<X^{2}$ tabel. Sesuai kriteria pengambilan keputusan, maka baik data pretest dan posttest dari kelas eksperimen maupun kelas kontrol keduanya berasal dari populasi yang terdistribusi normal.

Hasil perhitungan analisis uji homogenitas postest dapat dilihat pada Tabel 4.

TABEL 4 HASIL UJI HOMOGENITAS POSTEST

\begin{tabular}{|c|c|c|}
\hline \multirow{2}{*}{ Uraian } & \multicolumn{2}{|c|}{ Posttest } \\
\hline & CS & HOA \\
\hline Nilai F Hitung & 6,74 & 7,77 \\
\hline Varuasi Hitung & \multicolumn{2}{|c|}{1,15} \\
\hline Nilai $F$ tabel $(a=0,05)$ & \multicolumn{2}{|c|}{1,69} \\
\hline Keputusan & \multicolumn{2}{|c|}{ Homogen } \\
\hline
\end{tabular}

Berdasarkan hasil uji homogenitas pada tabel 4, dengan derajat kebebasan untuk pembilang $\left(n_{1}\right)=40$ dan penyebut $\left(n_{2}\right)=37$ pada taraf signifikansi $\alpha=0,05$, maka nilai $F_{\text {tabel }}$ diperoleh sebesar $\mathrm{F}_{0,05(40,37)}=1,69$ dan nilai ini lebih besar dari nilai $F_{\text {hitung }}=1,15$. Berdasarkan kriteria pengambilan keputusan, diketahui data tersebut memiliki varians yang sama atau homogen.

Hasil perhitungan analisis uji beda rata-rata (dua pihak) posttest menunjukkan bahwa ratarata skor hasil belajar siswa yang belajar dengan model pembelajaran simulasi komputer sama dengan rata-rata skor pembelajaran hands on activity. Sehingga dapat disimpulkan bahwa siswa pada kelas eksperimen CS dan kelas eksperimen HOA memiliki hasil belajar berbeda yang signifikan.

Hasil perhitungan analisis uji beda rata-rata (dua pihak) Postest dapat dilihat pada Tabel 5.
TABEL 5 UJI BEDA RATA-RATA (DUA PIHAK) POSTEST KELAS EKSPERIMEN CS DAN KELAS EKSPERIMEN HOA

\begin{tabular}{ccccc}
\hline \multirow{2}{*}{ Kelas } & $\begin{array}{c}\text { Nilai rata- } \\
\text { rata } \frac{X}{X}\end{array}$ & thitung & tabel & Keputusan \\
\hline CS & 14,41 & & & \\
\hline HOA & 12,25 & 3,60 & 1,67 & $\begin{array}{c}\mathrm{H}_{1} \\
\text { diterima }\end{array}$ \\
\hline
\end{tabular}

Berdasarkan data Tabel 5 dan kriteria pengujian dimana $\mathrm{H}_{0}$ ditolak jika $\mathrm{t} \geq \mathrm{t}_{(1-\mathrm{a})}$ dapat dilihat nilai thitung berada di luar daerah penerimaan $\mathrm{H}_{0}$. Dengan demikian $\mathrm{H}_{0}$ ditolak dan $\mathrm{H}_{1}$ diterima. Dengan kata lain, rata-rata skor hasil belajar siswa yang belajar dengan model Simulasi Komputer lebih besar dari rata-rata skor Hasil belajar siswa yang belajar dengan model pembelajaran Hands On Activity. Sehingga dapat disimpulkan bahwa siswa pada kelas eksperimen dan kelas kontrol memiliki kemampuan akhir yang berbeda.

\section{B. Pembahasan}

Berdasarkan analisis kuantitatif, hasil uji normalitas posttest kelas eksperimen CS dan kelas eksperimen HOA keduanya berdistribusi normal karena memenuhi kriteria penerimaan $x$ 2hitung $<x$ 2tabel. Selanjutnya hasil uji homogenitas disimpulkan bahwa tidak terdapat perbedaan varians antara kelas eksperimen dan kelas kontrol atau dengan kata lain kedua kelas dikatakan homogen.

Selanjutnya, untuk melihat perbedaan hasil belajar siswa menggunakan uji perbedaan ratarata. Sebelum melakukan uji perbedaan syarat yang harus dipenuhi adalah data harus berdistribusi normal dan homogen. Oleh karena data yang diperoleh dari perhitungan terdistribusi normal dan homogen, maka dilakukan uji perbedaan rata- rata menggunakan uji-t (dua pihak). Tabel 4.4 menunjukkan bahwa nilai thitung $=3,60>$ ttabel $=1,67$. Sesuai dengan kriteria penerimaan, maka dapat dikatakan bahwa rata- rata hasil belajar antara siswa kelas eksperimen CS lebih baik dari pada kelas eksperimen HOA. Dengan demikian HO ditolak dan $\mathrm{H} 1$ diterima hal ini menunjukkan bahwa terdapat perbedaan yang signifikan antara ratarata nilai kelas eksperimen CS dan kelas eksperimen HOA, jadi dapat disimpulkan bahwa terdapat perbedaan yang signifikan antara penerapan model pembelajaran CS dan model pembelajaran HOA.

Skor rata-rata siswa pada kelas eksperimen CS lebih tinggi dibandingkan skor rata-rata siswa pada kelas eksperimen HOA. Hal ini dapat terjadi karena pada kelas eksperimen CS diberlakukan sebuah pembelajaran yang menggunakan komputer sebagai alat bantu. Melalui pembelajaran ini bahan ajar disajikan melalui media komputer yang membuat kegiatan proses 
belajar mengajar menjadi lebih menarik dan menantang bagi siswa sehingga siswa akan lebih memahami materi yang diajarkan. pembelajaran berbasis komputer adalah salah satu media pembelajaran yang sangat menarik dan mampu meningkatkan motivasi belajar peserta didik.[4]

Pengalaman kerucut Dale memperlihatkan pengalaman dari yang bersifat langsung hingga ke pengalaman melalui simbol-simbol komunikasi, yang merentang dari yang bersifat kongkrit ke abstrak, dan tentunya memberikan implikasi tertentu terhadap pemilihan metode dan bahan pembelajaran, khususnya dalam pengembangan Teknologi Pembelajaran. Kerucut pengalaman Dale tersebut memperlihatkan bahwa untuk melakukan hal yang nyata, melakukan simulasi, dan bermain peran memiliki taraf daya inggat yang sama yaitu sebesar $90 \%$. Namun dalam penelitian ini menunjukan bahwa Simulasi Komputer (melakukan simulasi) memperlihatkan hasil belajar yang lebih tinggi dari pada Hands On Activity (melakukan hal nyata), kemungkinan gaya belajar dan motivasi siswa bisa berubah seiring dengan berkembangnya IPTEK yang menyebabkan siswa yang menggunakan Simulasi Komputer memiliki hasil yang lebih tinggi di bandingkan siswa yang belajar menggunakan Hands On Activity. [5]

Penelitian ini sejalan dengan penelitian sebelumnya dimana dalam penelitiannya didapatkan bahwa pemahaman siswa lebih meningkat jika menggunakan simulasi computer dibandingkan dengan hans on. Oleh karena itu simulasi computer sangat efektif digunakan sebagai media pembelajaran.[6]

Sesuai dengan penelitian terdahulu yang penelitiannya menyatakan bahwa siswa memiliki pemahaman yang lebih baik saat simulasi komputer digunakan dengan menjawab sesuai konsep dan pemahaman mereka sendiri.[7]

Keuntungan menggunakan model pembelajaran CS adalah dapat mengakomodasi siswa yang lamban karena dapat menciptakan iklim belajar yang efektif dengan cara yang lebih individual. Dapat merangsang siswa untuk mengerjakan latihan karena tersedianya animasi grafis, warna dan musik. Kendali berada pada siswa sehingga kecepatan belajar dapat disesuaikan dengan tingkat kemampuan.[8]

Mengacu pada beberapa keuntungan yang diperoleh tersebut, maka penggunaan komputer dalam pembelajaran diyakini dapat lebih meningkatkan hasil belajar dan motivasi belajar siswa di bandingkan dengan Hands On Activity. Peningkatan hasil belajar dan motivasi balajar siswa secara langsung merupakan indikator efektivitas dan efesiensi pelaksanaan pembelajaran. Oleh karena itu, pengembangan pembelajaran berbasis komputer dalam pembelajaran merupakan hal yang sangat penting dan harus di lakukan oleh guru.

\section{KESIMPULAN}

Terdapat pengaruh hasil belajar fisika antara model pembelajaran Simulasi Komputer dengan model pembelajaran Hands On Activity pada siswa kelas XI SMA Negeri 3 Palu. Hal ini ditunjukkan dengan kriteria penerimaan Ho adalah thitung $=3,60>$ ttabel $=1,67$. Hasil uji hipotesis ini memperlihatkan bahwa harga thitung tidak berada di dalam daerah penerimaan Ho atau dengan kata lain $\mathrm{H} 1$ diterima pada taraf nyata $a=0,05$, secara kuantitatif untuk kelas eksperimen (CS) lebih unggul dari kelas eksperimen (HOA). Dengan demikaian dapat dinyatakan bahwa hasil belajar dengan mengunakan model pembelajaran Simulasi komputer berbeda secara signifikan dari kelompok siswa yang mendapatkan pembelajaran Hands On Activity pada kelas XI SMA Negeri 3 Palu.

\section{DAFTAR PUSTAKA}

[1] Desmita, Rezki. (2014). Pendidikan Sebagai Wahana Sumber Daya Manusia Untuk Menjadi Indonesia Lebih Baik [Online]. Tersedia: https://rezkidesmita .blogspot. co.id/2014/01/pendidikan-sebagai-wahana-sumber-daya .html[1 Mei 017]

[2] Awak, Uda. 2015. Peranan Fisika dalam Perkembangan Teknologi. [Online]. Tersedia: http://www.Matrapendidikan .com/2015/06/perananfisika-dalam-perkembangan.html[1 Mei 2017]

[3] Amin, Mohamad. (2007). Apa Itu Hands On Activity. [Online]. Tersedia: https://lubisgrafura.wordpress.com /2007/09/08/apa-itu-hands-on-activity/[1 Mei 2017]

[4] Andrian, Fitri. (2015). Pembelajaran Berbasis Komputer. [Online]. Tersedia: http://fitriandrianmyblog.blogspot.co. id/2015/03/pembelajaran-berbasis-komputer .html [25 Februari 2016].

[5] Bagus, Radyan. (2014) .Kerucut Pengalaman (Cone Of Experience) Edgar Dale. [Online]. Tersedia:https: //bagusdwiradyan.wordpress.com/2014/07/06/ kerucutpengalaman-cone-of-experience-edgar-dale/[1Mei 2017]

[6] Sarabando. Cravino, jose P. dan Soares, Armando A. (2014)." Contribution of a computer simulation to students' learning of the physics concepts of weight and mass". Didactics and Technology in Education of Trainers" (CIDTFF), Aveiro, Portugal.

[7] Dancy, Melissa H. (2006). Impact of animation on assessment of conceptual understanding in physics. Department of Physics, University of North Carolina at Charlotte, Charlotte, North Carolina 28223, USA.

[8] Andrian, Fitri. (2015). Pembelajaran Berbasis Komputer. [Online]. Tersedia: http://fitriandrianmyblog.blogspot. co.id/2015/03/pembelajaran-berbasis-komputer .html [25 Februari 2016]. 